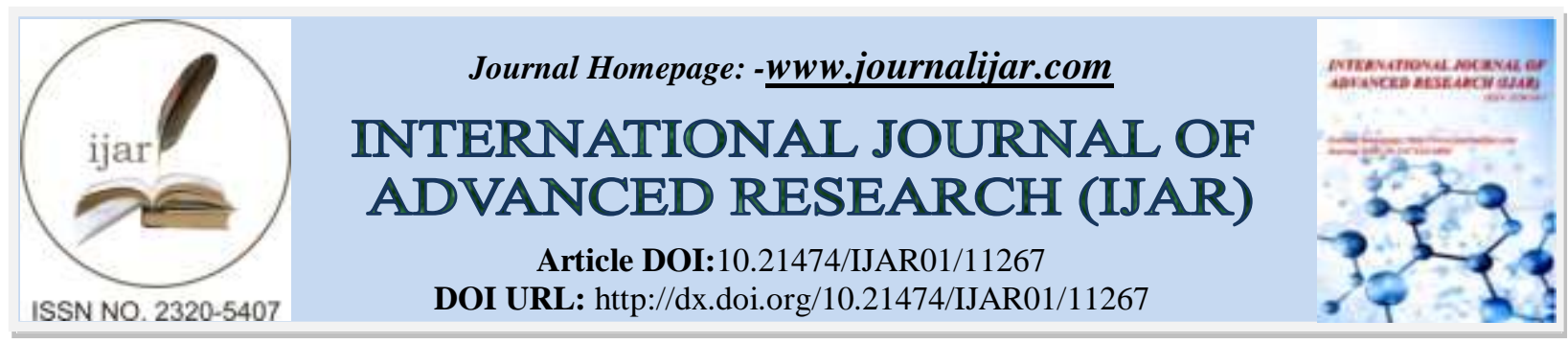

RESEARCH ARTICLE

\title{
SEASONAL VARIATION AT OUAGADOUGOU STATION FROM 1966 TO 1998 DURING GEOMAGNETIC SHOCK ACTIVITY: COMPARISON WITH IRI-2012 PREDICTIONS
}

Abdoul-Kader Segda ${ }^{1}$, Jean Louis Zerbo ${ }^{1,2}$, Doua Allain Gnabahou ${ }^{1}$ and Frédéric Ouattara ${ }^{1}$

1. Laboratoire de Recherche en Energétique et Météorologie de l'Espace (LAREME) Université Norbert Zongo, BP 376, Koudougou, Burkina Faso.

2. Laboratoire de Matériaux, d'Héliophysique et Environnement (LaMHE), Université Nazi Boni, Bobo Dioulasso, 01 BP 1091 Bobo, Burkina Faso.

\section{Manuscript Info}

Manuscript History

Received: 05 May 2020

Final Accepted: 10 June 2020

Published: July 2020

Key words:-

Critical Frequency (foF2), IRI-2012,

Amplitude, Shock Events, Profiles

\begin{abstract}
This paper presents the critical frequency foF2 behavior using in situ data and predicted one with IRI-2012 subroutines CCR and URSI during the solar cycles 21 and 22 under shocks conditions. Our investigations allowed us to identify the five types of profiles according to Faynot and Villa (1979) and observed important characteristics about foF2 amplitude seasonal variation during each solar cycle phase. The amplitudes of each type of profile depend on solar cycle phase and season. Lowest amplitudes are recorded during summer for all phases and seasons. The highest amplitude and observed during winter/ autumn for all the solar cycle phases except for solar minimum phase where maximum is observed on spring. A gap in the amplitude is observed most of the time between in situ measured data and IRI predictions. Concordance between measured data profiles and predictions is about $42.85 \%$ with CCIR and $64.28 \%$ with URSI. The different profiles obtained are characteristics of the presence or absence of electrojet phenomenon during morning or afternoon as reviewed by Vassal and al. (1982).
\end{abstract}

Copy Right, IJAR, 2020,. All rights reserved.

\section{Introduction:-}

It is well-known that the F2 layer is one of the most important parts of the ionosphere for the propagation of radio waves due to its height and electron density. One of the useful parameters used to get a global overview of this ionospheric layer is its critical frequency foF2.To achieve this goal, empirical models of prediction such as International Reference Ionosphere (IRI) have been developed in the 1960s by Committee on Space Research (COSPAR) and International Union of Radio Science (URSI). Its goal is to establish an international standard for fundamental ionospheric parameters (Bilitza and Reinisch, 2007). This model has been progressively improved over time and it is internationally considered nowadays as a standard for ionospheric parameters and used in many review (Bilitza and Reinisch, 2007; Oyekola and Fagundes , 2012 ; Bilitza et al.,2014; Ouattara and Nanéma 2014; Abidina et al., 2019; Sawadogo et al., 2019; Guibula et al., 2019). Its 2012 version has been used to conduct many comparative studies between the ionospheric measured parameters and predicted one with IRI-model two subroutines URSI (Union Radio Scientifique Internationale) and CCIR (Comité Consultatif International des Radio Communications). Investigation at Ouagadougou ionosphere station in Burkina Faso (Lat: $12.5^{\circ} \mathrm{N}$, Long: $358.5^{\circ}$ E, dip: $1.43^{\circ}$ ) may contribute to the improvement of ionospheric parameters prevision in equatorial zone. Certain 
authors (Adeniyi1 et al. 2005; Oyekola and Fagundes, 2012; Ouattara et al., 2012; Ouattara and Nanéma, 2014) have reviewed on similar subject.

Our present work reviews on comparative investigation on foF2 parameter variations obtained from the 2012 IRI model and in situ measurements from Ouagadougou station under solar shock activity condition during the time interval 1966 to 1998.

The section 2 of this paper is devoted to Data and Methods and the section 3 shows results and discussion.

\section{Data and Methodology:-}

\section{Data:}

Critical frequency foF2 dataare used for this study. In situ data aremeasurements from Ouagadougou ionsonde station and predicted data are obtained with IRI-2012 two subroutines URSI and CCIR. The shocks days have been identified mean to pixel diagram fully discussed by Legrand and Simon (1989), Ouattara and Mazaudier (2009), Zerbo et al. (2012), Zerbo et al. (2013), Gyébré et al (2015). Figure 1 is an example of pixel diagram showing the four geomagnetic activity classes. Shock events correspond to the dates of SSCs where the geomagnetic index Aa > $40 \mathrm{nT}$.

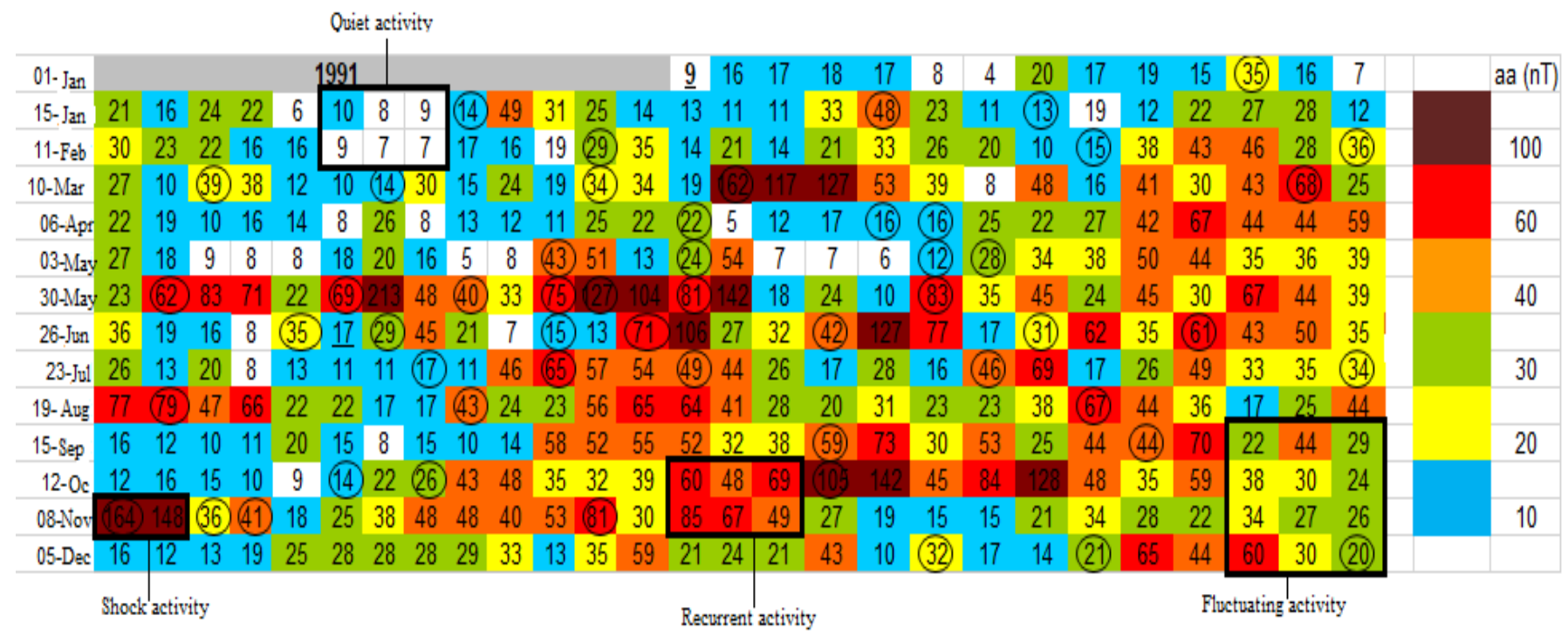

Figure 1:- Pixel diagram four year 1991.

\section{Methodology:-}

Our method of analysis consists on comparison between measured foF2 and predictions with IRI-2012 subroutines URSI and CCIR through: (1) a morphological study based on temporal behavior of foF2 in agreement with different types of profile reviewed by Faynot and Villa (1979). (2) Quantitative analysis based on a comparison between measurement and predictions. We appreciate the gap between in situ measurements and predictions mean to the percentage of deviation $(\% \mathrm{D})$ given by $\% \mathrm{D}=\frac{\mathrm{x}_{\mathrm{i}}^{\mathrm{m}}-\mathrm{x}_{\mathrm{i}}^{0}}{\mathrm{x}_{\mathrm{i}}^{0}} \times 100$, where $\mathrm{x}_{\mathrm{i}}^{0}$ and $\mathrm{x}_{\mathrm{i}}^{\mathrm{m}}$ are predicted and measured data respectively (Nanéma, 2016).

\section{Results and Discussion:-}

The figures presented in this section show the temporal profiles of in situ data and predictions with IRI-2012 subroutines URSI and CCIR. Each figure presents profiles and percentage of deviation for the four seasons (winter, spring, and summer, and autumn). The Figures 2 to 5 present seasonal variability of foF2 during the solar cycle minimum, increasing, maximum, and decreasing, respectively, phases over the solar cycles 21 and 22. 


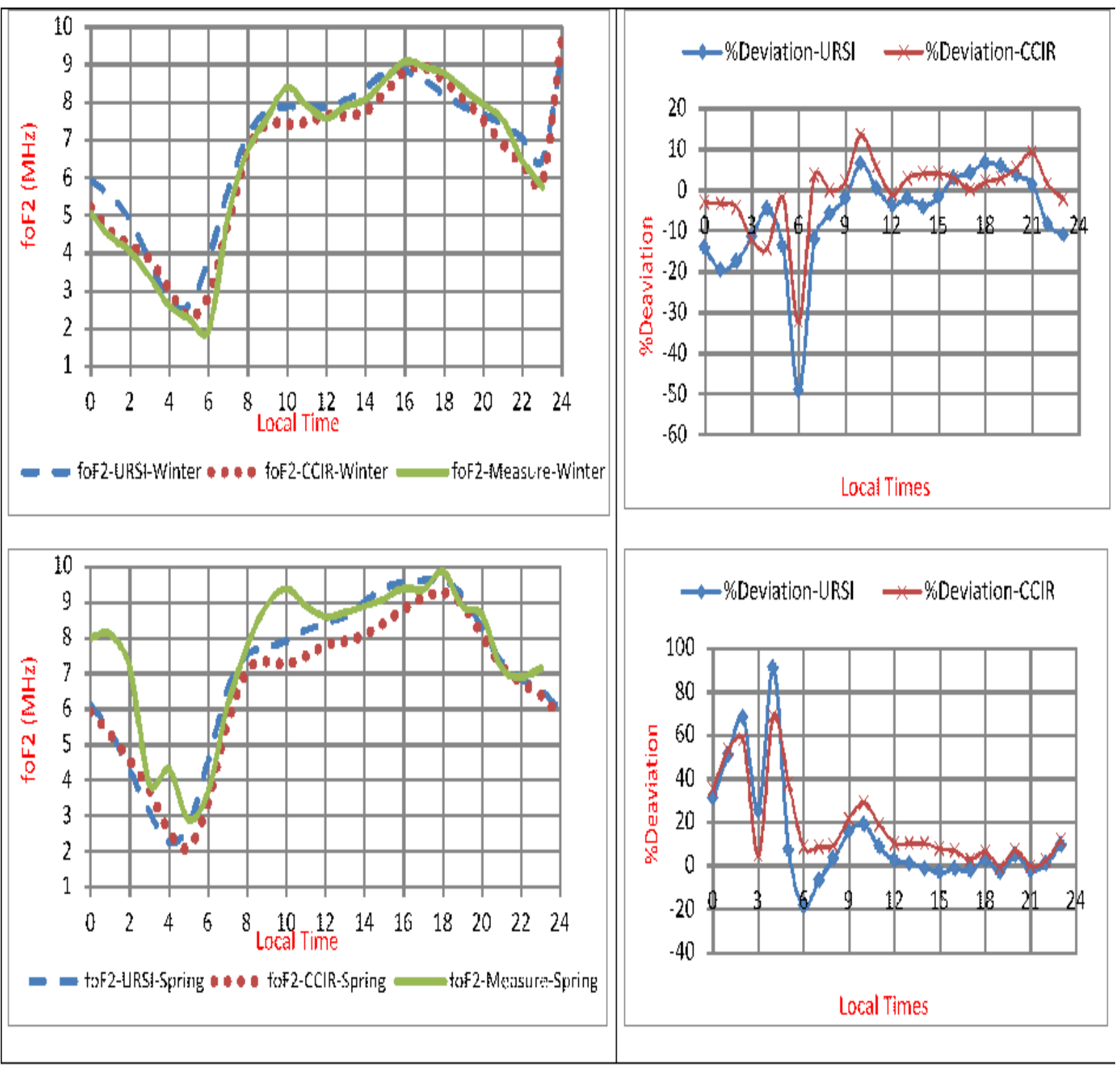

Figure 2:- foF2 profiles during solar minimum phase of solar cycle 21 and 22. 


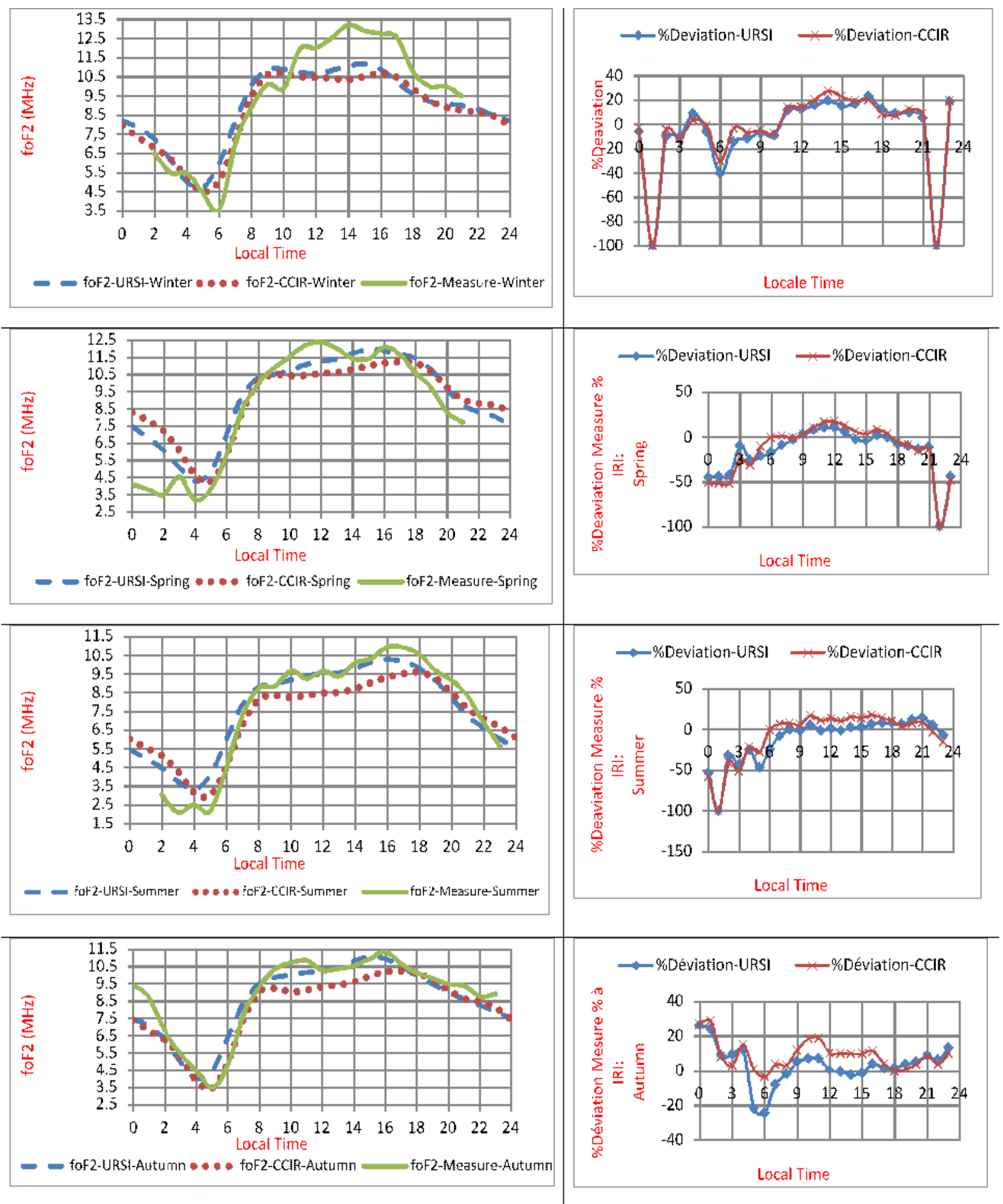

Figure 3:- foF2 profiles during solar increasing phase of solar cycle 21 and 22. 

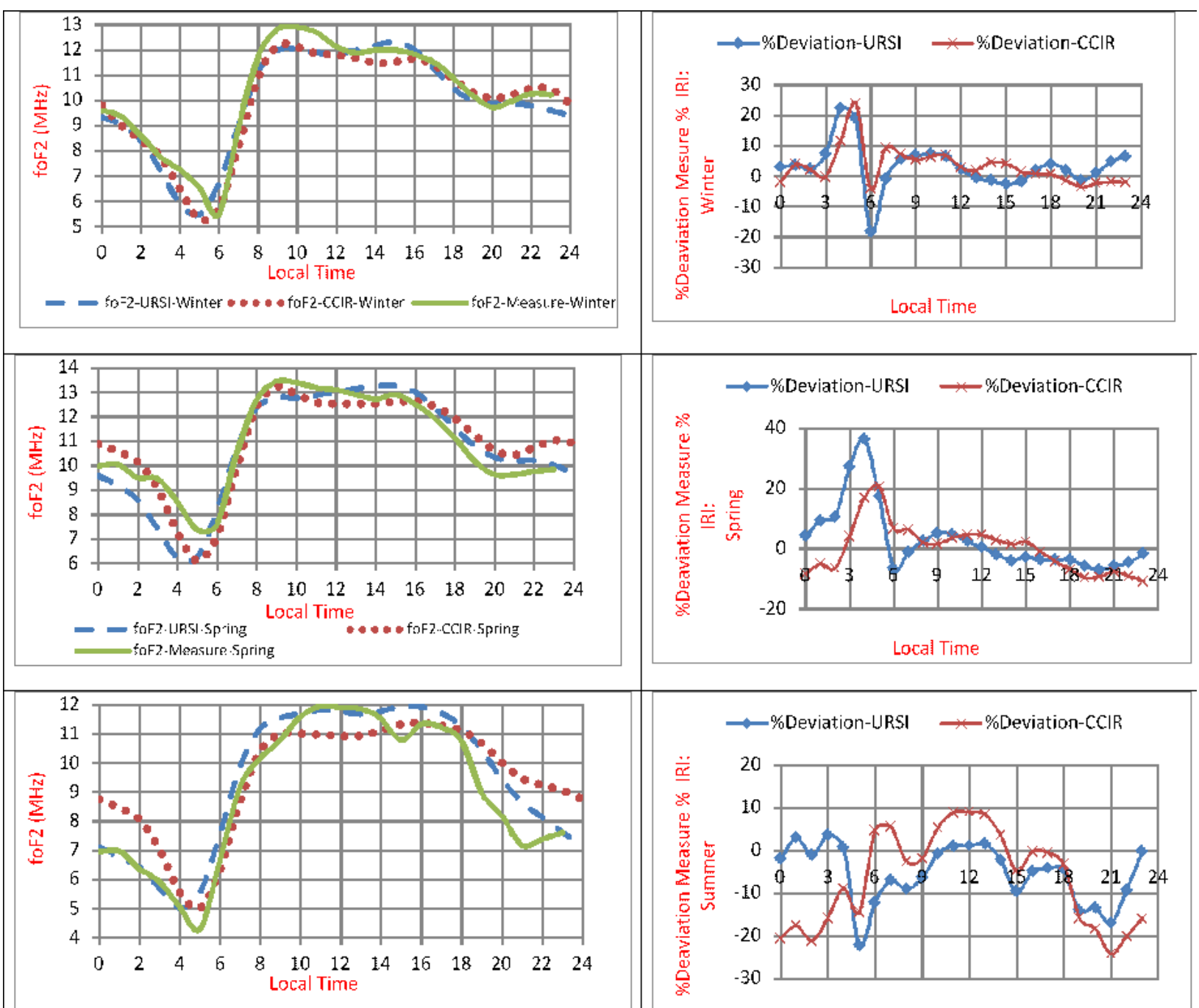

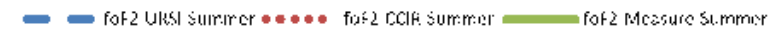
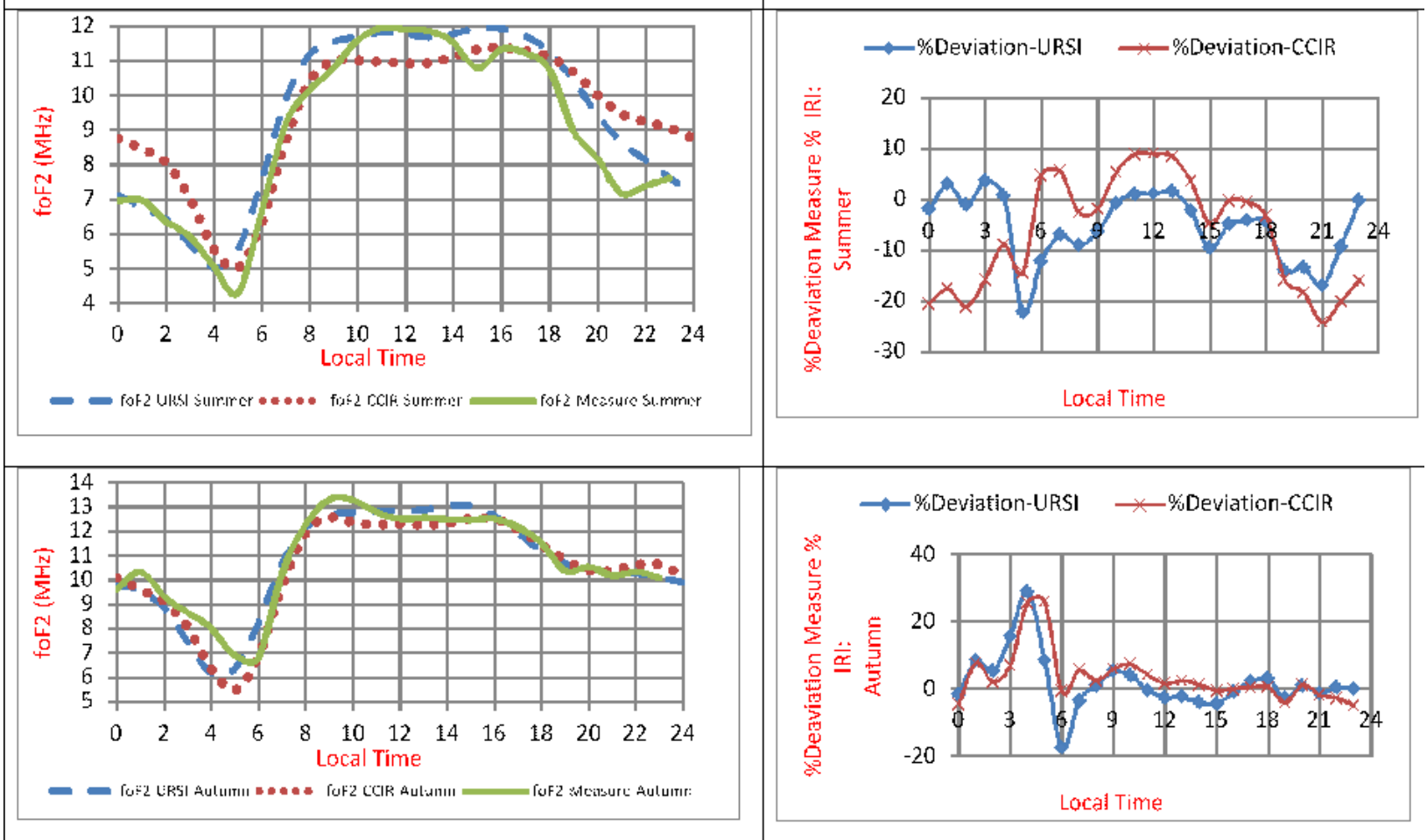

Figure 4:- foF2 profiles during solar maximum phase of solar cycle 21 and 22. 

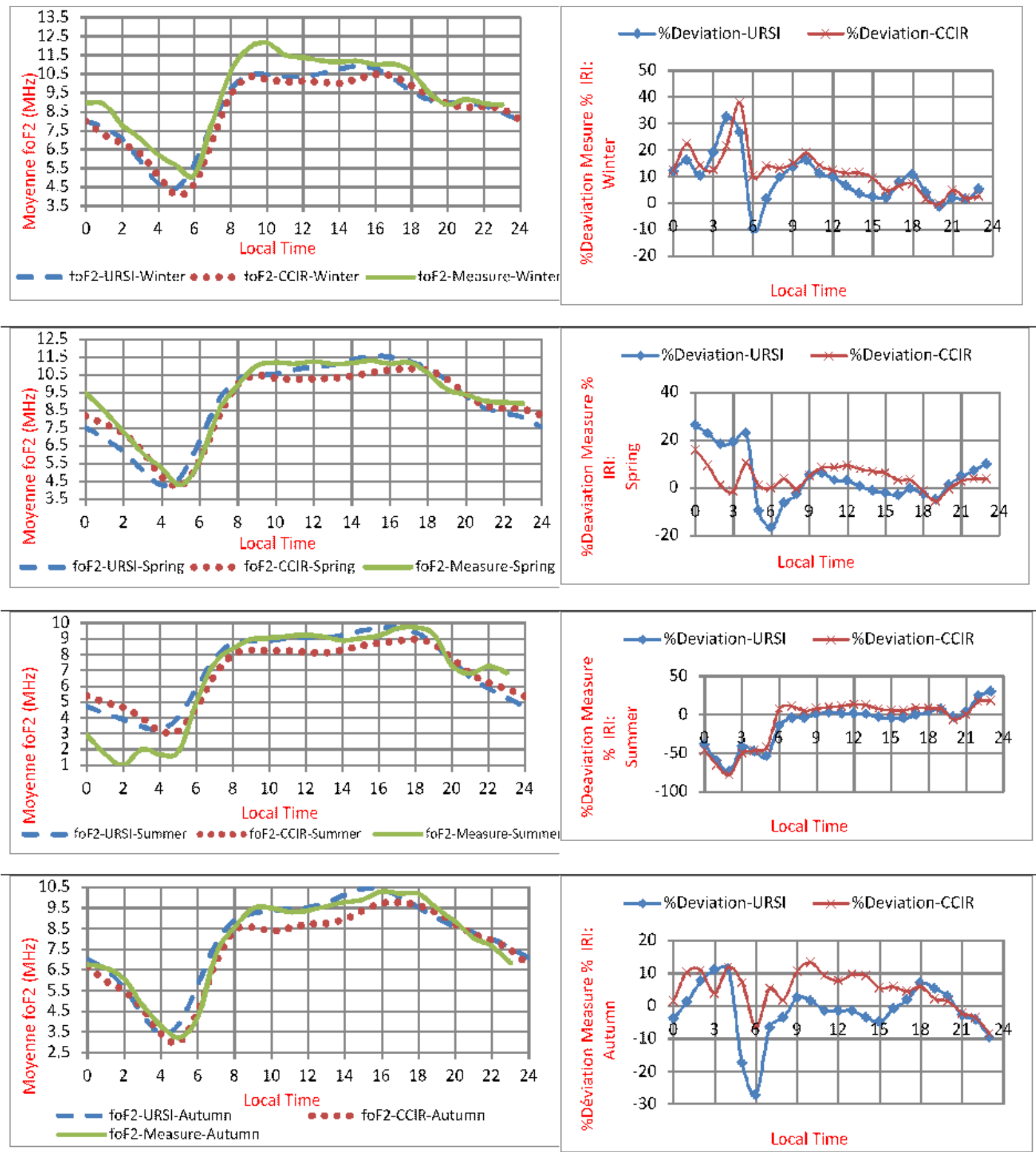

Figure 5:- foF2 profiles during solar decreasing phase of solar cycle 21 and 22.

\section{Morphological study:}

At solar cycle minimum phase (Figure 2), in situ measurements variation shows " $R$ " profile during winter and spring which are the only seasons with available data during this phase. The same profile is exhibited by predicted data with URSI and CCIR. Thus there is morphological concordance between in situ measurements and predictions at solar minimum phase for all the seasons investigated.These profiles show night peaks around 2300 LT with CCIR predictions during winter and night peaks around $2200 \mathrm{LT}$ for in situ measurements during spring. Taking a look to the relative deviation percentage $\left(\left|\sigma_{\text {rel }}\right| \leq 10 \%\right.$, for each season, it appears that predictions with URSI during winter and spring show about $66.67 \%$ of concordance with in situ measurements. At the same time and for winter and spring, respectively, predictions with CCIR $83.33 \%$ and $50 \%$ of agreement with in situ data. Considering criteria of 
concordance (Nanéma, 2016;Adewale et al.,2010) we can assume that URSI predictions is closer to in situ measurements compared to those with CCIR, even if better agreement is obtained with CCIR during winter.

Figure 3 presents foF2 seasonal variation during solar cycle increasing phase. During this solar cycle phase, in situ measurements exhibit "D" profile, "B" profile, "R" profile, and "R" profile (Faynot and Villa, 1979) respectively during winter, spring, summer and autumn. During the same period URSI and CCIR predictions giveboth the profiles of types "B" profile for winter and"R" profile for the three other seasons (spring, summer and autumn). On can see concordance ("R" Profile) between in situ measurements and predictions with IRI-2012 for foF2 profile during summer and autumn. The profiles also present night peaks around $2200 \mathrm{LT}$ for in situ data and CCIR predictions during autumn spring, respectively. Considering the percentage of deviation (figure 3 , right panels) we can see good agreement $\left(\left(\left|\sigma_{\text {rel }}\right| \leq 10\right)\right.$ between IRI-2012 two subroutines prediction with in situ measurements two seasons (Summer and autumn): in summer,62. 5\% and in autumn ,75\% of agreement for URSI; CCIR show in winter $50 \%$ and in autumn 58, 33\% of agreement (Nanéma, 2016). These results show that URSI predictions is closer to in situ data for all the seasons and URSI better model ionosphere critical frequency foF2 during solar increasing phase.

Figure 4 presents foF2 behavior during solar maximum phase for different seasons. In situ data profiles present " $\mathrm{M}$ " profile for winter, spring, and autumn; and " $\mathrm{D}$ " profile during summer. Predictions with URSI give "B" profile during winter and summer; and "R" profile during spring and autumn. With CCIR predictions profiles are "M" profile for winter, spring, and autumn; and " $\mathrm{B}$ " profile during summer. There is very good concordance between in situ data and predictions with CCIR during winter, spring, and autumn with night peaks around 2300 LT.we can see remarkable concordance between in situ data and predictions with IRI-2012. CCIR shows in winter 91.67\%, in spring $87.5 \%$, in summer $58.33 \%$ and in autumn $91.67 \%$ of agreement between predicted data and in situ measurements with a percentage of deviation $\left|\sigma_{\text {rel }}\right| \leq 10 \%$. With URSI, investigations show $87.5 \%, 83.33 \%$, $79.17 \%$ and $87.5 \%$ of agreement during winter, spring, summer and autumn respectively. Here CCIR seems closer to in situ measurements than URSI during solar Maximum phase. According to RMSE (Adewale et al.,2010), URSI predictions are in agreement with in situ data only during summer compared to CCIR predictions which are in good agreement with in situ measurements during the seasons of winter, spring and autumn. During the solar cycle phase CCIR model has better performance than URSI for ionospheric parameters predictions.

Figure 5 presents the seasonal profiles of foF2 in situ data and IRI-2012 prediction during solar decreasing phase. Interesting profiles are shown in this figure. During this solar cycle phase, in situ data present " $M$ " profile during winter, "P" profile during spring and, "R" profile for both summer and autumn while URSI predictions exhibit"R" profile for all the seasons. With CCIR we have obtained "B" profile for both winter and spring; and "R" profile during both summer and autumn. We observe good concordance between predictions with IRI-2012 and in situ data ("R" profile) during summer and autumn. In addition prediction and in situ measurements profiles show night peaks check around 2200 LT without exception. Analyzing the percentage of deviation (Figure 5, right panel) we can see that IRI-2012 two subroutines URSI and CCIR predictions are in good agreement with in situ measured data: $\left|\sigma_{\text {rel }}\right| \leq 10$. According to the relative deviation, URSI predictions are closer to in situ measurements for all the seasons in comparison with CCIR where concordance is well expressed only during winter, summer and autumn. This result shows that URSI better predicts ionospheric parameters during solar decreasing phase. According to criteria of performance RMSE, well reviewed by Adewale et al.,2010, URSI better predicts foF2 variations during solar decreasing phase for all seasons.

Our investigations have out lighted the five types of profile (B, D, M, P) reviewed by Faynot and Vila (1979). The "M" profile obtained with in situ measurements and IRI-2012 subroutines testifies to the presence of an electrojet during the morning and weakness against electrojet during the afternoon (Vassal, 1982). The "R"profile means that we have had strong against electrojet during the afternoon and weakness electrojet during morning of these seasons. The profile B means that we have had electrojet during the morning and another during the afternoon of these seasons. The "D" profile given by only measure in situ during summer means that only summer is characterized by the absence of significantmagnetic activities, in opposite to the "P" profile obtained only with measured in situ data during spring. The night peaks recorded around 2200 LT or 2300 LT with in situ and CCIR measurements indicate the reverse of electric field $\mathrm{E} \times \mathrm{B}$, an important characteristics of equatorial regions (Farley, D.T., et al., 1986; Rishbeth, H et al.,1971; Fejer, B.G., et al., 1979). 


\section{Qualitative study:}

An investigation on the maximum amplitude of the different curves presented in this paper points out interesting observations:

During solar minimum phase (Figure 2), the highest amplitudes are obtained in spring with foF2 in situ measurements $(9.61 \mathrm{MHz})$ and URSI predictions $(9.86 \mathrm{MHz})$; and the lowest $(9.30 \mathrm{MHz}$ and $9.08 \mathrm{MHz})$ in winter. CCIR predictions maximum amplitudes are recorded in winter and the lowest amplitudes during spring $(9.73 \mathrm{MHz}$ and $9.27 \mathrm{MHz}$ respectively).

For solar increasing phase (Figure 3), it appears that the lowest amplitudes of foF2 data are obtained during summer. At the same time, the highest amplitude are recorded in winter with foF2 in situ data (13.2 MHz) and in spring with URSI and CCIR predictions (11.87 MHz and 11.24 MHz). Observations during solar maximum phase (Figure 4) show that the more significant low values of foF 2 are recorded most of the time in summer. For this same solar cycle phase, important amplitudes in foF2 profiles are observed during spring and autumn: in situ measurement (13.44 MHz and 13.30 MHz respectively in spring and in autumn); URSI predictions (13.27 MHz and $13.04 \mathrm{MHz}$ respectively in spring and in autumn); CCIR prediction (13.22 MHz and $13.57 \mathrm{MHz}$ respectively in spring and in autumn). During the solar cycle decreasing phase (Figure 5) the lowest amplitudes are obtained as well as for in situ data and IRI predictions in summer. The highest amplitudes are recorded at different seasons: winter for foF2 in situ measurement (12.14 MHz), spring for IRI two subroutines URSI $(11.54 \mathrm{MHz})$ and CCIR $(10.84 \mathrm{MHz})$. All these remarkable characteristics may be due to various physical phenomenon. The minimum amplitude observed during summer for all the solar cycles phases may be explained by the fact that the Earth is so far from Sun at that seasonas reviewed by Ouattara and al. (2009) about the close link between solar cycle and foF2 variation. The maximum amplitude depend on the season and the solar cycle phase. Except on solar minimum phase where maximum amplitude is observed during spring all the maximum occurred in winter and for few in autumn. During these seasons, Earth is closer to Sun. additional phenomenon such as high stream solar wind, coronal mass ejections (CME) which are characteristics of active solar activity (Legrand and Simon, 1989; Zerbo et al., 2012, 2013) can explain the behavior of foF2 during solar maximum and decreasing phases during these two solar cycle phases, the sunspot bring important irradiation to the atmosphere.

\section{Conclusion:-}

We have studied critical frequency foF2 behavior using in situ data and predicted one with IRI-2012 subroutines CCR and URSI. The investigation allowed us to identify the five types of profiles reviewed by Faynot and Villa (1979). The amplitudes of each type of profile depend on solar cycle phase and season. Lowest amplitudes are recorded during summer for all phases and seasons. The highest amplitude and observed during winter/ autumn for all the solar cycle phases except for solar minimum phase where maximum is observed on spring. A gap in the amplitude is observed most of the time between in situ measured data and IRI predictions. This testifies to the necessity to improved IRI-2012 model for equatorial region as suggested by many authors (Sawadogo et al., 2019, Guibula et al., 2019). All these variations observed in foF2 profiles can be affected by the presence or absence of electrojet during morning or during afternoon by the solar eruption (Vassal). With these investigations, we can see that URSI better predicts foF2 performance.

\section{Conflicts of interests}

The authors have not declared any conflicts of interests.

\section{Acknowlegements:-}

The authors thank Brest Telecom for providing Ouagadougou ionosonde data and ISGI data centre for providing the aa indices. They thanks the IJAR editorial office and the anonymous reviwers.

\section{References:-}

1. Adeniyi,J.O. andAdimula,I.A.(1995):Comparingthe F2-layer model ofIRIwith observations atIbadan. Advanced inSpaceResearch 15:141-144. https://doi.org/10.1016/S0273-1177(99)80036-2

2. Adewale, A.O., Oyeyemi, E.O., Ofuase, U.D. (2010): Comparison between observed ionospheric foF2 and IRI2001 predictions over periods of severe geomagnetic activities at Grahamstown, South Africa. Advances in Space Research,45(3):368-373;https://doi.org/10.1016/j.asr.2009.09.026 
3. Bilitza D, and Reinisch BW. International Reference Ionosphere 2007 (2008): Improvements and new parameters. Advances in Space Research. 42, pp. 599-609.doi:10.1016/j.asr.2007.07.048

4. Bilitza, D., Altadill, D.,Zhang, Y., Mertens, C., Truhlik, V., Richards, P.,McKinnell L.A., and Reinisch, B. (2014): The International Reference Ionosphere 2012 - a model of international collaboration. J. Space Weather Space Climate. A07: 1-12. https://doi.org/10.1051/swsc/2014004.

5. Diabaté A.,Zerbo, J.L., and Ouattara F(2019): Variation of the foF2 parameter during fluctuating activity: Prediction with IRI-2012 compared to measured data from Ouagadougou inosonde station during solar cycles 21 and 22. Vietman Journal of Earth Sciences 41, 1, pp 69-78.doi: 10.15625/0866-7187/41/1/13549.

6. Farley,D.T.,Bonell,E.,Fejer,B.G.,Larsen,M.F.(1986):ThePrereversalEnhancement ofthe ZonalElectricFieldintheEquatoriallonosphere.JournalofGeophysicalResearch,91:1372313728.http://dx.doi.org/10.1029/JA091iA12p13723

7. Faynot, J. M and Vila, P. (1979) F-Region at the Mahnetic Equator. Annales geophysicae, 35, 1-9.

8. Fejer,B.G.,Farley,D.T.,Woodman,R.F.andCalderon,C.(1979).DependenceofEquatorialFregionVerticalDriftsonS easonandSolarCycle.JournalofGeophysicalResearch84:5792- 5796.https://doi.org/10.1029/JA084iA10p05792

9. Gyébré, A.M.F., Ouattara, F., Kaboré, S. and Zerbo, J.L. (2015):Time variation of shock activity due to moderate and severe CMEs from 1966 to 1998. British Journal of Science, vol. 13 (1) 1-7.

10. Guibula, K., Zerbo, J.L., Kaboré, M. and Ouattara, F. (2019): Critical frequency foF2 variations at Korhogo station from 1992 to 2001 prediction with IRI-2012. International Journal of Geophysics, vol.2019, pp11.https://doi.org/10.1155/2019/2792101

11. Ouattara, F. and Nanéma,E.(2014):QuiettimefoF2variationatOuagadougoustationand comparisonwithTIEGCMandIRI-2012predictionfor1985and1990.PhysicalScience International Journal,4: 892902,ISSN: 2348-0130. http://www.sciencedomain.org.

12. Ouattara, F. and Amory-Mazaudier, C. (2009): Solar- geomagnetic Activity and Aa indices toward a standart classification. Journal of Atmospheric and Solar-Terrestrial Physics. 71:1736-1748.doi: 10.1016/j.jastp.2008.05.001

13. Ouattara, F., Gnabahou, D. A and Mazaudier, CA. (2012) Seasonal, Diurnal and Solar- Cycle Variation of Electron Density and Two West Africa Equatorial Ionization Anomaly Stations. International Journal of Geaophsics, vol.2012, Article ID: 640463.

14. Ouattara, F., Amory Mazaudier, C., Fleury. R., lassudrie-Duchesne, P., Vila, P. and Petitdidier, M. (2009) West African equatorial ionospheric parameters climatology based on Ouagadougou ionosonde station data from June 1966 to February 1998. Annales Geophysicae, 27, 2503-2514.

15. Oyekola, O.S. and Fagundes, P. R.(2012): Equatorial F2-layer variations: Comparison between F2 peak parameters at Ouagadougou with the IRI-2007 model. Earth, Planets Space, 64, 553-566.

16. Legrand, J.P. and Simon,P.A. (1989) Solar and Geomagnetic Activity: A review for Geophysicists. Part 1. The Contributions to Geomagnetic Activity of Shock Waves and of Solar Wind. Annals of Geophysics, 7,6, 565-578.

17. Nanema, E;(2016) : Modélisation deNmF2, foF2 et hmF2 à la station de Ouagadougou aucoursducyclesolaire22parTIEGCM1.94etIRI-2012etappréciationdeleursprédictions. Thèsededoctorat unique, UFR/SEA, Université deOuagadougou

18. Rishbeth, . H.(1971) :TheF-LayerDynamo.PlanetaryandSpaceScience, 19:263267.http://dx.doi.org/10.1016/0032-0633(71)90205-4

19. Sawadogo, W.E., Zerbo, J.L. and Ouattara, F. (2019) Diurnal variation of F2-layer critical frequency under solar activity recurrent conditions during solar cycles 21 and 22 at Ouagadougou station: Prediction with IRI2012. Scientific Research and Essays,Vol.14 (11), pp 111-118.doi: 10.5897/SRE2019.6636 111-118

20. Vassal, J.A.(1982) :Electrojet,contre-électrojetet régionFàSarh(Tchad). Géophysique. ORSTOM, Paris. http://www.documentation.ird.fr/hor/fdi:02756

21. Zerbo, J.L., Amory-Mazaudier, C. Ouattara, F. and Richardson, J.(2012): Solar Wind and Geomagnetism, toward a Standard Classification 1868-2009. Annales Geophysicae; Vol. 30, pp. 421426.http://dx.doi.org/10.5194/angeo-30-421-2012

22. Zerbo, J.L., Amory-Mazaudier, C. and Ouattara, F. (2013): Geomagnetism during solar cycle 23: Characteristics. Journal of Advanced Research; vol 4,Issue 3, pp 265-274 doi:10.1016/j.jare.2013.08.010. 